\title{
Insights into the Origin of High Activity and Stability of Catalysts Derived From Bulky, Electron-Rich Monophosphinobiaryl Ligands in the Pd- Catalyzed C-N Bond Formation
}

\author{
Eric R. Strieter, Donna G. Blackmond, and Stephen L. Buchwald* \\ Department of Chemistry, Massachusetts Institute of Technology, Cambridge, \\ Massachusetts 02139 and Department of Chemistry, University of Hull, Hull, HU6 7RX, \\ U.K.
}

\section{Supporting Information}

\section{General Considerations}

Reagents: $\operatorname{Pd}(\mathrm{OAc})_{2}$ and ligand 5 were purchased from Strem Chemical Co. and used without further purification. Ligands $\mathbf{1}-\mathbf{4}$ were prepared as previously described. ${ }^{1}$ $\mathrm{NaOt}$-Am was purchased from Aldrich. $p$-Chlorotoluene 6 was purchased from Aldrich and distilled from $\mathrm{CaH}_{2}$ prior to use. Morpholine 7 was also purchased from Aldrich and distilled from $\mathrm{CaH}_{2}$ prior to use. $\mathrm{d}_{8}$-Morpholine $\mathbf{d}_{8}-\mathbf{7}$ was purchased from Cambridge Isotope Laboratories, Inc. All reagents were handled and stored under nitrogen in a Vacuum Atmosphere glovebox. Toluene was purchased from J.T. Baker in CYCLETAINER $^{\circledR}$ solvent delivery kegs, which were vigorously purged with argon for $2 \mathrm{~h}$, and further purified by passing the solvent through two packed columns of neutral alumina and copper (II) oxide under argon pressure.

Reaction procedure. Reactions were performed in a stirred $16 \mathrm{~mL}$ screw capped vial with a PTFE septa under a positive pressure of argon. The reaction vial (typically 2.1 $\mathrm{mL}$ or $4.2 \mathrm{~mL}$ reaction volume) was placed in the sample compartment of a Omnical SuperCRC reaction calorimeter with an empty vial placed in the reference compartment. The stirred vial was maintained under isothermal conditions at $353 \mathrm{~K}$. The calorimeter recorded the difference in heat flows from the sample vs. reference cells at data collection rates up to $60 \mathrm{~min}^{-1}$. A typical reaction was conducted by adding four identical aliquots of $6\left(4 \times[6]_{\circ}=0.15 \mathrm{M}\right)$ in four different intervals to a thermally equilibrated reaction mixture consisting of $4.2 \mathrm{mM}$ of $\mathrm{Pd}(\mathrm{OAc})_{2}, 9.2 \mathrm{mM}$ of ligand, $0.8 \mathrm{M}$ of NaOt-Am, $0.75 \mathrm{M}$ of 7 and dodecane as an internal standard. Another reaction protocol consisted of adding a mixture of $7\left([7]_{\circ}=0.75 \mathrm{M}\right)$ and the first aliquot of $6\left([6]_{\circ}=0.15 \mathrm{M}\right)$ to the thermally equilibrated catalyst/NaOt-Am mixture and allowing for complete conversion of the aryl chloride before the next aliquot of $\mathbf{6}$ was added (a total of four identical aliquots of 6 were added to the reaction). The reaction mixture was in each case an orange solution.

\footnotetext{
1 (a) Tomori, H.; Fox, J.M.; Buchwald, S.L. J. Org. Chem. 2000, 65, 5334-5341. (b) Kaye, S.; Fox, J.M.; Hicks, F.A.; Buchwald, S.L. Adv. Syn. Catal. 2001, 343, 789-794. (c) Huang, X.; Anderson, K.A.; Zim, D.; Jiang, L.; Klapars, A.; Buchwald, S.L. J. Am. Chem. Soc. 2003, 125, 6653-6655.
} 
Kinetic data analysis: The use of reaction calorimetry to study reaction kinetics has been described previously. ${ }^{2}$ An energy balance around the reaction vessel demonstrates that for the case of a single reaction occurring, the reaction heat flow, $q$, is proportional to the reaction rate, $r$, where $\Delta \mathrm{H}_{\mathrm{rxn}}$ is the heat of reaction and $\mathrm{V}$ is the reaction volume (eq. 1).

$$
q=\Delta H_{r x n} \cdot V \cdot r
$$

The heat of reaction from integration of the observed heat flow vs. time curves and gave an average value of $188 \mathrm{~kJ} / \mathrm{mole} \pm 5 \%$ for all four consecutive reactions. The observed heat flow profiles were used to obtain the fractional conversion of 6 by calculation of the fractional area under the temporal heat flow curve by equation 2 , where the numerator represents the area under the heat flow to any time point $t$ and the denominator represents the total area under the heat flow curve.

$$
\text { fractional conversion }=\frac{\int_{0}^{t} q \cdot d t}{\int_{0}^{t_{f}} q \cdot d t}
$$

Kinetic parameters were determined by fitting the reaction rate data obtained from the heat flow to an analytical rate equation using the Solver program in Excel (Microsoft).

2 (a) Blackmond, D.G.; McMillan, C.R.; Ramdeehul, S.; Schorm, A.; and Brown, J. J. Am. Chem. Soc. 2001, 123, 10103. (b) Rosner, T.; Sears, P.J.; Nugent, W.A.; Blackmond, D.G. Org. Lett. 2000, 2, 2511. (c) LeBlond, C.;Wang, J.; Larsen, R.D.; Orella, C.J.; Forman, A.L.; Landau, R.N.; Laquidara, J.; Sowa, Jr., J.R.; Blackmond, D.G.; Sun, Y.-K. Thermochim. Acta 1996, $289,189$. 